\title{
PEMBUATAN DAN KARAKTERISASI KATALIS TIO2/KARBON AKTIF DENGAN METODE SOLID STATE
}

\author{
Upita Septiani $^{\mathrm{a}}$, Mega Gustiana ${ }^{\mathrm{a}}$, dan Safni ${ }^{\mathrm{b}}$ \\ ${ }^{\text {a }}$ Laboratorium Kimia Material Jurusan Kimia FMIPA, Universitas Andalas \\ ${ }^{\mathrm{b}}$ Laboratorium Analisis Terapan Jurusan Kimia FMIPA, Universitas Andalas \\ Email: upitas@yahoo.com
}

\begin{abstract}
Composite catalyst of $\mathrm{TiO}_{2} /$ Activated Carbon $\left(\mathrm{TiO}_{2} / \mathrm{AC}\right)$ had been synthesized with successfully by solid-state method. Synthesis was done by varying the addition of AC 5\%,10\% and $15 \%$ of the mass of $\mathrm{TiO}_{2}$ was used. Composite catalyst was calcinated at temperature $400^{\circ} \mathrm{C}$ and characterized by Fourier Transform Infra-Red (FTIR), X-Ray Diffraction (XRD) and Scanning Electron Microscopy (SEM). FTIR spectrum show that the absorption appearedin the regionof $\mathrm{C}=\mathrm{C}$ at wave number $1600-1800 \mathrm{~cm}^{-1}$, that assumed from AC. From XRD we can see that with variated of AC do not given different XRD patterns significantly, crystal structure of composite catalyst is anatase. SEM images showed that $\mathrm{AC}$ prevented the aglomeration of $\mathrm{TiO}_{2}$ that would expand surface area and increased catalytic activity of $\mathrm{TiO}_{2}$.
\end{abstract}

Keywords: activated carbon,composite, catalyst, rhodamin $\mathrm{B}$, solid state, $\mathrm{TiO}_{2}$

\section{PENDAHULUAN}

$\mathrm{TiO}_{2}$ banyak digunakan sebagai fotokatalis karena $\mathrm{TiO}_{2}$ bersifat inert, stabilitas termalnya baik, non-toksik, tahan pada temperatur tinggi, aktifitas katalitiknya cukup baik.Aktifitas fotokatalitik dari $\mathrm{TiO}_{2}$ dapat ditingkatkan dengan memodifikasi struktur, luas permukaan dan ukuran partikel dengan menambahkan ion dopan. Salah satu modifikasi $\mathrm{TiO}_{2}$ adalah dengan menambahkan karbon ${ }^{[1-7]}$.

Kabon yang ditingkatkan dayanya melalui aktivasi disebut karbon aktif, memiliki luas permukaan yang cukup besar dan memiliki sifat adsorbsi yang cukup baik, sehingga bisa digunakan sebagai adsorben, sifat karbonaktif ini dapat membantu proses adsorbsikatalitik $^{[8,9]}$.

Penelitian tentang $\mathrm{TiO}_{2} /$ karbon aktif pernah dilakukan oleh Andayani dan Sumartono (2006), katalis $\mathrm{TiO}_{2} /$ Cyang disintesa dengan proses sol-gel dan diimobilisasi pada pelat titanium, katalis dibuat dengan rasio $\mathrm{TiO}_{2} / \mathrm{C}$ $8 / 2$ dan $5 / 5$, karbon aktif dapat meningkatkan aktivitas katalitik dariTiO ${ }_{2}{ }^{[8]}$.

Dalam penelitian ini dilakukan pembuatan katalis $\mathrm{TiO}_{2} /$ karbon aktif dengan metode solid state, kemudian katalis yang dihasilkan dikarakterisasi dengan FTIR (Fourier Transform InfraRed), XRD (X-Ray Diffraction), SEM (Scanning Electron Microscopy).

\section{METODOLOGI PENELITIAN}

Bahan yang digunakan dalam penelitian ini yaitu, $\mathrm{TiO}_{2}$ anatase (Ishihara Sangyo Kaisha LTD, JAPAN), karbonaktif (Merck), dan akuades.

Alat yang digunakan dalam penelitian ini yaitu, XRD (Philip X'pert Powder dengan sumber target $\mathrm{Cu} K$ ), SEM 
(Phenom Pro X), FTIR (Evolution 201 UV-Visible Spectrophotometer).

\section{Prosedur penelitian}

Preparasi Sampel $\mathrm{TiO}_{2}$

$\mathrm{TiO}_{2}$ diaktifasi dengan cara dipanaskan pada temperatur $200 \quad{ }^{\circ} \mathrm{C}$ menggunakan oven selama 4 jam.

\section{Preparasi KatalisTiO ${ }_{2} / \mathrm{KA}$}

Komposit $\mathrm{TiO}_{2} /$ karbon aktif $\left(\mathrm{TiO}_{2} / \mathrm{KA}\right)$ dibuat dengan Rasio $\mathrm{TiO}_{2}$ : karbon aktif, yaitu $95 \%: 5 \%, 90 \%: 10 \%$ dan $85 \%: 15 \%$. Katalis dikalsinasi pada temperatur $400{ }^{\circ} \mathrm{C}$ selama 6 jam.

\section{HASIL DAN DISKUSI}

\section{Karakterisasi dengan FTIR}

Gambar (1) merupakan spektrum FTIR dari $\mathrm{TiO}_{2}$, karbon aktif dan katalis $\mathrm{TiO}_{2} / \mathrm{KA}$ denganvariasiKA $5 \%$ wt, $10 \%$ wtdan $15 \%$ wt. Spektroskopi infra merah merupakan suatu metode analisis yang digunakan untuk mengidentifikasi gugus fungsi, komposisi kimia dan tipe ikatan berdasarkan vibrasi atom dalam molekul.

Gambar (1.a) memperlihatkan spektrum FTIR $\mathrm{TiO}_{2}$ murni. Spektrum ini memperlihatkan adanya serapan yang kuat pada aerah 400-1000 $\mathrm{cm}^{-1}$ yang menunjukkan adanya ikatan Ti-O-Ti, ini mengindikasikan formasi kerja dari titanium dioksida. Selanjutnya pada daerah 3200-3600 $\mathrm{cm}^{-1}$ merupakan vibrasi $\mathrm{O}-\mathrm{H}$ stretching dari molekul $\mathrm{H}_{2} \mathrm{O}$ yang teserap pada permukaan $\mathrm{TiO}_{2}$.

Gambar (1.b) memperlihatkan spektrum FTIR karbon aktif murni. Pada daerah kisaran gelombang $3399 \mathrm{~cm}^{-1}-3441 \mathrm{~cm}^{-1}$ menunjukkan adanya gugus hidroksil $(-\mathrm{OH})$ pada karbon aktif., tidak adanya pita-pita serapan pada kisaran daerah sidik jari 700 $800 \mathrm{~cm}^{-1}$ menunjukkan bahwa karbon aktif bukan merupakan senyawa yang mengandung rantai alkil panjang ${ }^{[9]}$.

Gambar (1.c, d, dan e) merupakan spektrum dari $\mathrm{TiO}_{2} / \mathrm{KA}$ dengan variasi KA 5\% wt, 10 wt, dan $15 \%$ wt, spektrum ketiga katalis ini relatif sama atau senada, dimana muncul spektrum yang sama dengan $\mathrm{TiO}_{2}$. Penambahan karbon aktif dengan beberapa variasi tidak memberikan perubahan pada spektrum $\mathrm{TiO}_{2}$, yaitu daerah serapan 450 $550 \mathrm{~cm}^{-1}$ menunjukkan adanya vibrasi ulur dari Ti-O, pada daerah $3400-3700 \mathrm{~cm}^{-1}$ merupakan stretching O-H dari molekul $\mathrm{H}_{2} \mathrm{O}$ yang terserap pada permukaan $\mathrm{TiO}_{2}$. Kemudian adanya serapan yang lemah didaerah 1600 -an $\mathrm{cm}^{-1}$ menunjukkan adanya stretching $\mathrm{C}=\mathrm{C}$ yang diasumsikan berasal dari karbon aktif. Hal ini dimungkinkan karena jumlah karbon aktif yang sedikit ${ }^{[10]}$.

\section{Karakterisasi dengan XRD}

Gambar (2) ini menunjukkan pola difraksi dari $\mathrm{TiO}_{2}$, karbon aktif dan katalis $\mathrm{TiO}_{2} / \mathrm{KA}$ dengan variasi $\mathrm{KA} 5 \% \mathrm{wt}, 10 \% \mathrm{wt}, 15 \% \mathrm{wt}$ yang dilakukan dengan alat XRD. Karakterisasi menggunakan XRD ini berguna untuk mengetahui struktur kristal katalis yang serta mengetahui ukuran kristal dari katalis.

Gambar (2.a) merupakan pola difraksi sinar$\mathrm{X}$ dari $\mathrm{TiO}_{2}$, dengan membandingkan data dari JCPDS No.01-072-7058, puncak-puncak $\mathrm{TiO}_{2}$ yang diukur menunjukkan kemiripan dengan puncak-puncak $\mathrm{TiO}_{2}$ pada JCPDS tersebut,ini mengindikasikan bahwa $\mathrm{TiO}_{2}$ memiliki struktur anatase, dengan ukuran kristal yang didapat dari perhitungan dengan menggunakan persamaan Scherrer yaitu, 14 $\mathrm{nm}$.

Dari gambar (2.b) dapat dilihat pola difraksi karbon aktif yang tidak menunjukkan puncak yang tajam, puncak tersebut memberikan informasi bahwa karbon aktif tidak berbentuk kristal, tetapi berbentuk amorf sesuai dengan data JCPDS, No.00-023-0064.

Pola difraksi sinar-X dari katalis $\mathrm{TiO}_{2} / \mathrm{KA}$ dengan variasi KA $5 \% \mathrm{wt}, 10 \% \mathrm{wt}$, dan $15 \%$ wt ditunjukkan oleh Gambar (2.c, d dan e) dari ketiga gambar dapat dilihat adanya puncak-puncak dengan pola yang sama dengan pola $\mathrm{TiO}_{2}$. Dari gambar dapat disimpulkan dengan adanya penambahan karbon aktif tidak berpengaruh pada bentuk pola difraksi sinar-X dari katalis, tetapi intensitas puncak dari $\mathrm{TiO}_{2}$ dengan penambahan variasi KA $5 \% \mathrm{wt}, 10 \% \mathrm{wt}$, dan $15 \%$ wt mengalami perubahan. Intensitas yang berbeda ini akan memberikan pengaruh 
pada ukuran kristal katalis, dimana ukuran kristal dari katalis $\mathrm{TiO}_{2}$ dan katalis komposit $\mathrm{TiO}_{2} / \mathrm{KA}$ dengan variasi 5 , 10 , dan $15 \%$ didapatkan dengan menggunakanp ersamaan Scherrer, ukuran kristal untuk $\mathrm{TiO}_{2} / \mathrm{KA}$ dengan variasi $\mathrm{KA} 5 \% \mathrm{wt}, 10 \% \mathrm{wt}, 15 \% \mathrm{wt}$ berturut-turut adalah 35 ; 45 ; dan $35 \mathrm{~nm}$.

\section{Karakterisasi dengan SEM}

Analisis SEM digunakan untuk menganalisis morfologi permukaan katalis, foto SEM dari $\mathrm{TiO}_{2}$, karbon aktif dan katalis $\mathrm{TiO}_{2} / \mathrm{KA}$ dengan variasi 5,10 dan $15 \%$ diperlihatkan pada Gambar 3.

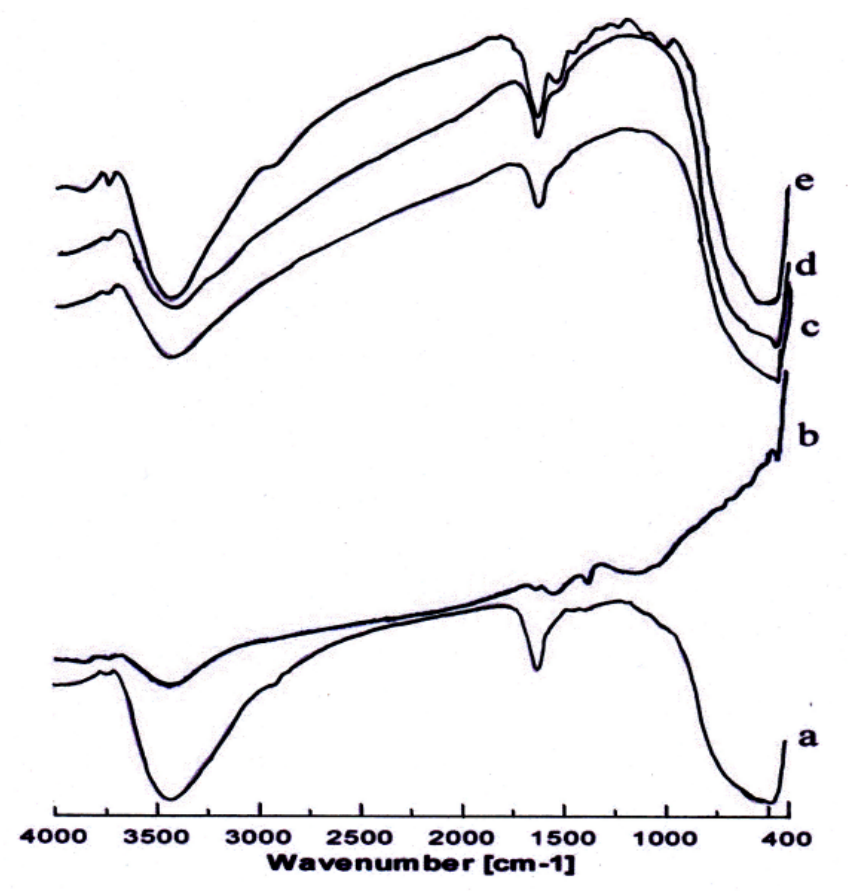

Gambar 1. Spektrum FTIR, a. $\mathrm{TiO}_{2}$, b. KarbonAktif, c. $\mathrm{TiO}_{2} / \mathrm{KA} 5 \%$, d. $\mathrm{TiO}_{2} / \mathrm{KA} 10 \%$, e. $\mathrm{TiO}_{2} / \mathrm{KA} 15 \%$.

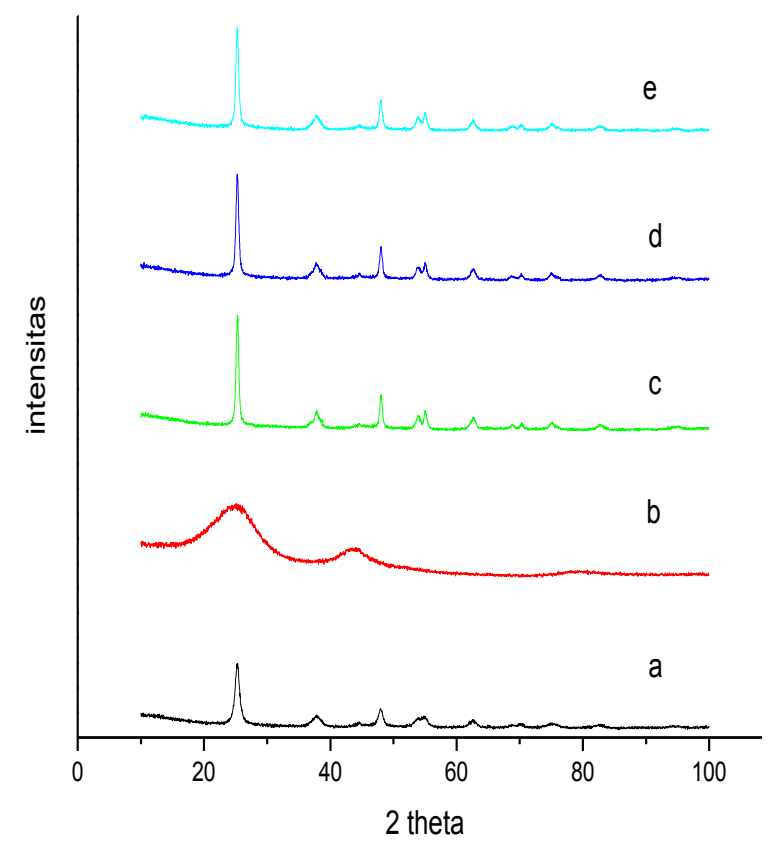

Gambar 2. Pola Difraksi dari, a. $\mathrm{TiO}_{2}$, b. Karbon Aktif, c. $\mathrm{TiO}_{2} / \mathrm{KA} 5 \%$, d. $\mathrm{TiO}_{2} / \mathrm{KA}^{10 \%}$, e. $\mathrm{TiO}_{2} / \mathrm{KA} 15 \%$. 


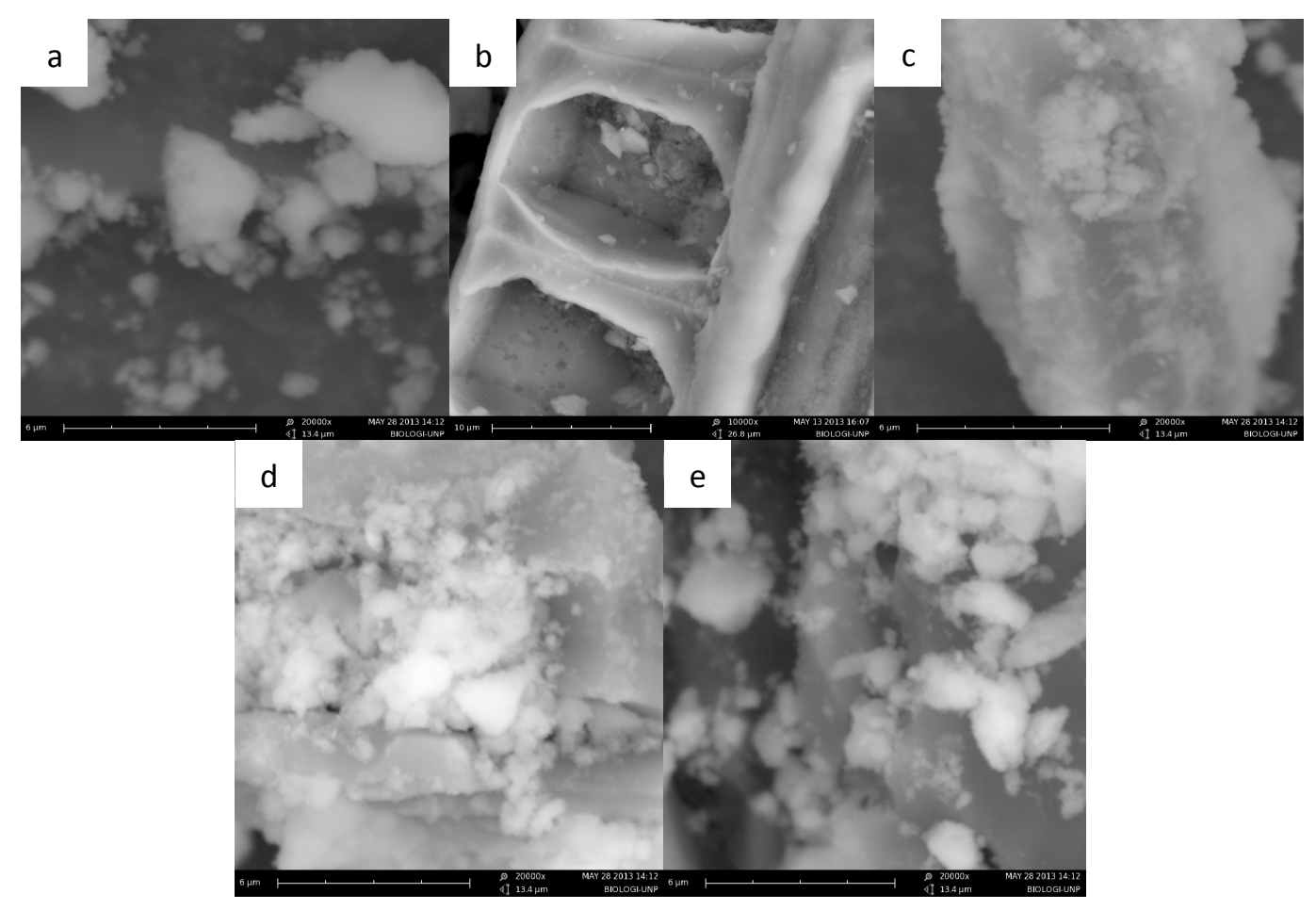

Gambar 3. Foto SEM dari, a. $\mathrm{TiO}_{2}$ (perbesaran 20000x), b. KarbonAktif (perbesaran 10000x),

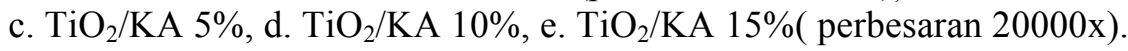

Gambar (3.a) merupakan gambar $\mathrm{TiO}_{2}$ murni pada perbesaran 20000x, dari foto SEM dapat terlihat partikel-partikel $\mathrm{TiO}_{2}$ menumpuk sesamanya, sehingga terlihat seperti gumpalan-gumpalan putih dengan ukuran yang tidak seragam. Gambar (3.b) merupakan foto SEM dari karbon aktif pada perbesaran 10000x, dari gambar dapat dilihat bahwa karbon berbentuk batangan dan memiliki pori.

Gambar (3.c, d dan e) merupakan foto SEM dari katalis $\mathrm{TiO}_{2} / \mathrm{KA}$ dengan variasi $\mathrm{KA} 5 \%$ wt, $10 \%$ wt, dan $15 \%$ wt. Dari gambar dapat dilihat bahwa $\mathrm{TiO}_{2}$ menempel dan menyebar pada permukaan karbon, dengan bertambahnya konsentrasi karbon menyebabkan penggumpalan antara sesama partikel-partikel $\mathrm{TiO}_{2}$ terhalang. Karbon dapat mengahalangi penumpukan yang terjadi pada sesama partikel $\mathrm{TiO}_{2}$, terhalangnya penumpukan partikel $\mathrm{TiO}_{2}$ ini diasumsikan akan menyebabkan luas permukaan partikel $\mathrm{TiO}_{2}$ semakin besar, yang nantinya akan meningkatkan aktivitas fotokatalitik $\mathrm{TiO}_{2}$.

\section{KESIMPULAN}

Katalis komposit $\mathrm{TiO}_{2} / \mathrm{KA}$ telah berhasil disintesis dengan metode solid state, dibuktikan dengan adanya data FTIR, XRD, dan SEM. Dari hasil FTIR, menunjukkan adanya serapan stretching $\mathrm{C}=\mathrm{C}$ yang diasumsikan berasal dari karbonaktif. Dilihat dari hasil XRD penambahan karbon aktif tidak berpengaruh pada bentuk pola difraksi sinar-X dari katalis, tetapi intensitas puncak dari katalis $\mathrm{TiO}_{2} / \mathrm{KA}$ dengan variasi $\mathrm{KA} 5 \%$ wt, $10 \%$ wt dan $15 \%$ wt mengalami perubahan, sehingga akan memberikan pengaruh pada ukuran kristal katalis. Hasil yang diperlihatkan oleh data SEM, karbon aktif dapat mencegah penggumpalan antara partikel-patikel $\mathrm{TiO}_{2}$, dimana partikel $\mathrm{TiO}_{2}$ menempel dan menyebar ke permukaan karbon aktif.

\section{DAFTAR PUSTAKA}

1. Ren, W., Zhihui, A., Falong, J., Lizhi, Z., Xiaoxing, F., and Zhigang, Z., Low temperature preparation and visible light photocatalytic activity of mesoporous 
carbon - doped crystalline $\mathrm{TiO}_{2}$, Appl. Catal. B: Envirom., 69: 138-144 (2007).

2. Zaleska, A. Doped- $\mathrm{TiO}_{2}$, Recent Patens on Engineering., 2: 157-164 (2008).

3. Azis, H., Admin, A., Safni., Syukri., dan Olly, N.T. Pengantar Fotokimia, Edisi I, Padang : Sukabina Press (2009).

4. Rahmayeni., Yeni, S., dan Zulhadjri. Fotokatalis Komposit Magnetik $\mathrm{TiO}_{2-}$ $\mathrm{MnFe}_{2} \mathrm{O}_{4}$. Prosiding Semirata FMIPA Universitas Lampung (2013).

5. Yang, Q., Liaou, Y., and Mao, L. (2012), Kinetics of photocalytic degradation of gaseous organic compounds on modified $\mathrm{TiO}_{2} / \mathrm{AC}$ composite photocatalyst, Chin. J. Chem. Eng., 20: 3, 572-576.

6. Zhou, W., Peng, Z., and Weian, L. Anatase $\mathrm{TiO}_{2}$ Nanospindle activated carbon (AC) composite photocatalyst with enhanced activity in removal of organic contaminant. Int. J. Photoenergy., 1-7 (2012).

7. Azhar, R.F., M. Wildan, B.Y., Syifa, F., Ucu, S., dan Widayati. (2009), Carbon, rofaneutron.files.wordpress.com/2010/0 9/carbon.docx. Diunduh pada 2 Agustus 2013.

8. Misbakhuddin, Pengaruh Ketebalan Karbon aktif sebagai media filter terhadap penurunank air sumur artetis, eksplanasi, 5(2): 1-11 (2010),

9. Andayani, W. dan Agustin, S., Karakterisasi Katalis $\mathrm{TiO}_{2}$ dan $\mathrm{TiO}_{2} /$ Karbon aktif yang diimobilisasi pada pelat titanium dan uji aktifitasnya sebagai fotokatalis, Jurnal Kimia Indonesia., 1(2): 54-58 (2006).

10. Stuart, B. Infrared Spectroscopy: Fundamentals and Apllications, John Willey and Sons. Ltd, 24 dan 28 (2004). 